\title{
Application of Pythagorean Fuzzy Digraphs in Package Delivery Robots
}

DOI:10.36909/jer.ICMMM.15913

\author{
Kanagaraj Sangeetha*, Mani Parimala ${ }^{* *}$, Mohammed A. Al Shumrani ${ }^{* * *}$ and Said Broumi ${ }^{* * * *}$
}

*Department of Mathematics, Bannari Amman Institute of Technology, Sathyamangalam638401, India

\section{Email: sangiprakash18@gmail.com}

** Department of Mathematics, Bannari Amman Institute of Technology, Sathyamangalam638401, India

Email: rishwanthpari@gmail.com , Corresponding Author.

*** Department of Mathematics, King Abdulaziz University, P.O.Box: 80203

Jeddah 21589, Saudi Arabia

E-mail: maalshmrani1@kau.edu.sa

**** Laboratory of Information Processing, Faculty of Science Ben M'Sik, University Hassan

II, Casablanca, Morocco

E-mail: broumisaid78@gmail.com

\begin{abstract}
The fuzzy set concept was developed to cope with uncertainty, whereas traditional sets are intended to deal with certainty. To address flaws in fuzzy set theory, extensions such as Intuitionistic Fuzzy Set (IFS), neutrosophic fuzzy sets, image fuzzy sets, and Pythagorean fuzzy set (PyFS) were developed. Pythagorean fuzzy set is useful tool for more clearly defining hazy concepts. In comparison to other fuzzy models, Pythagorean fuzzy set-based models allow more flexibility in handling human judgement information. The fuzzy graph structure is used to deal with the uncertainty in a network and to characterize its relationship with the non-empty vertex set. Pythagorean fuzzy graph (PyFG) was one of the Intuitionistic Fuzzy Graph (IFG) extensions. PyFG was created to cope with the uncertainty of an object
\end{abstract}


and its relationship with other objects. PyFS and PyFG are the driving forces behind this innovative concept. This work defines Pythagorean Fuzzy Digraph (PyFDG), and PyFDG's score function. An algorithm is proposed for an issue to find the Pythagorean shortest path in package delivery robots.

Key words: Fuzzy Set; Intuitionistic Fuzzy Graph; Pythagorean Fuzzy Set; Pythagorean Fuzzy Graph; Pythagorean Fuzzy Digraphs

\section{INTRODUCTION}

Graph theory is a mathematical technique for studying the relationship between things and solving network problems (node). Rosenfeld clarified the concept of graph theory in a hazy situation(Rosenfeld, 1975). Researchers further established fuzzy graph operations and types, such as a fuzzy graph's complement, regular fuzzy graph, and so on. Atanassov defined IFS as a generalised fuzzy set with two types of membership: active and inactive(Atanassov, K.,\&Stoeva, S., 1983). A fuzzy set differs from a regular set in that the elements of the set have a membership value. It was discovered in 1965 by (Zadeh,L.A., 1965). Shannon and Atanassov established the concepts of IFR and IFG as generalizations of fuzzy graphs (FG) (Shannon, A., Atanassov, K., 2006). Intuitionistic fuzzy graph and shortest path issue were constructed by Parvathi et al. and Karunambigai et al. in an intuitionistic fuzzy environment(Parvathi\&Karunambigai, 2006, Parvathi et al.,2009\&Parvathi\&Thamizhendhi, 2010).

However, while IFSs have been found as useful in a variety of disciplines, they do have significant limits. The Truth and False membership values are limited by IFSs, with the total of true and false memberships not exceeding 1. PyFS was created to address a limitation, and (Yager,R.R., 2013,Yager,R.R., Abbasov,A.M., 2013 \&Yager,R.R., 2014) offered this theory, which includes an active $(\mu)$ and an inactive $(\vartheta)$ are two different types of memberships both having the situation $\mu^{2}+\vartheta^{2} \leq 1$. The Pythagorean fuzzy number was created by $(\mathrm{Xu}, \mathrm{Z}$, Hu,H.,2010 \&Zhang,X., Xu,Z., 2014)to clarify an element's twin characteristics. 
When the two types of membership: active and inactive grades are both 0.9 and 0.3 , respectively, Zhang and Xu's technique fails to resolve the decision-making conundrum. PyFG operations and attributes were recently examined by Akram et al. (Akram,M., Habib,A., Ilyas,F., Dar,J.M., 2018). In a fuzzy Pythagorean setting, Akram et al. presented the idea of a planar graph. Muhammad Akram et al. (Akram,M., MohsanDar,J., Naz,S., 2019) introduced and investigated the maximum product of two PyFG's, as well as the qualities of the residual product of two PyFG's. (Özdemir,Y.S., Üsküdar,A,. 2020)provides a fuzzy logic-based prediction technique for time series prediction that uses nearest neighbourhood clustering. Using group decision-making, (Shahzad,M.,2020) proposes a new strategy selection model.

PyFG was investigated as a generalised notion of IFG by Naz et al., (Naz,S., Ashraf ,S., Akram,M., 2018) as well as the application of the proposed notion. (Broumi.Set al2019) introduced a hesitancy fuzzy digraph-based network shortest path algorithm. Fuzzy graph operations and types were defined by (Mordeson, J.N.,Chang-Shyh,P,. 1994). (NagoorGani and Radha 2008) identified some features of regular fuzzy graphs. (Karunambigai,M.G., Rangasamy,P., Atanassov,K., and Palaniappan,N., 2018)investigated intuitionistic fuzzy graph method for finding the shortest paths in networks. (Parimala,M., Almunajam,A., Karthika,M., Alshammari,I.,2021)reviewed application problem in Healthcare Center by using Pythagorean fuzzy digraph.

The goal of this research is to present a scoring system for a Pythagorean fuzzy digraph, as well as a decision-making algorithm for addressing problems using this concept. Finally, use a real-world case to test the suggested technique. This publication may motivate researchers to investigate a variety of real-world issues using the proposed algorithm.

In section 2, we give preliminary definitions and the definition for Pythagorean fuzzy set, Pythagorean Fuzzy graph, Pythagorean fuzzy diagraph that we will utilize in our study. In section 3, the generated algorithm is used to solve a decision-making problem and also we 
instigate flow chart. In section 4, the developed algorithm is used to tackle an application problem. In section 5, presents the conclusion and discusses further research.

\section{PRELIMINARIES}

We will review and present some fundamental ideas about Pythagorean fuzzy sets that are well-known in the literature in this session.

Definition (Rosenfeld, A., 1975)

Fuzzy Set over the universe $\mathrm{X}$ is an object $A=\left\{a, \mu_{A}(a): a \in X\right\}$, for each element a $\in \mathrm{X}$, the mapping $\mu_{A}: X \rightarrow[0,1]$ is referred to as the membership function of $\mathrm{A}$.

Definition (Atanassov, K., 1986)

Assume V is a non-empty vertex set.

The fuzzy set's mappings $\mathrm{N}: \mathrm{V} \rightarrow[0,1]$ on $\mathrm{V}$ as well as the relationship $\mathrm{E}: \mathrm{V} \times \mathrm{V} \rightarrow[0,1]$ on $\mathrm{V}$ as a result $\mu_{E}\left(a_{1} a_{2}\right) \leq \mu_{N}\left(a_{1}\right) \Lambda \mu_{N}\left(a_{2}\right)$,for every $a_{1}, a_{2} \in$ Vare denoted by $\mathrm{G}=(\mathrm{N}, \mathrm{E})$.

The symbol $\Lambda$ denotes the smallest operator.

Definition (Zadeh,L.A., 1985)

I is an intuitionistic fuzzy set in X (world of discourse) (IFS).

$$
I=\left\{\left\langle x, \mu_{I}(x), \vartheta_{I}(x)\right\rangle / x \in X\right\}
$$

Where $\mu_{I}: X \rightarrow[0,1]$ represents the level of membership and $\vartheta_{I}: X \rightarrow[0,1]$ represents the level of non- membership, respectively, and for any $x \in X$ fulfill the requirement

$$
0 \leq \mu_{I}(x)+\vartheta_{I}(x) \leq 1
$$

And the degree of indecision for any IFS I and $x \in X$ is given by

$$
\pi_{I}(x)=1-\mu_{I}(x)-\vartheta_{I}(x) .
$$

Definition (Zhang,X., Xu,Z., 2014)

$\mathrm{N}$ in $\mathrm{X}$ (universe of discourse) is called a Pythagorean fuzzy set (PFS).

$$
N=\left\{\left\langle x, \mu_{N}(x), \vartheta_{N}(x)\right\rangle / x \in X\right\}
$$

Where $\mu_{N}: X \rightarrow[0,1]$ represents the level of membership and $\vartheta_{N}: X \rightarrow[0,1]$ represents the level of non- membership, respectively, and for any $x \in X$ fulfill the requirement 


$$
0 \leq \mu_{N}^{2}(x)+\vartheta_{N}^{2}(x) \leq 1
$$

And the degree of indecision for any PFS $\mathrm{N}$ and $x \in X$ is given by

$$
\pi_{N}(x)=\sqrt{1-\mu_{N}^{2}(x)-\vartheta_{N}^{2}(x)}
$$

The limitation corresponding to the degree of membership $\mu_{N}(x)$ and the degree of nonmembership $\vartheta_{N}(x)$ in the case of PFS.

$$
0 \leq \mu_{N}^{2}(x)+\vartheta_{N}^{2}(x) \leq 1
$$

In the case of IFS, however, the situation is $0 \leq \mu_{I}(x)+\vartheta_{I}(x) \leq 1$

For $\mu_{N}(x), \vartheta_{N}(x) \in[0,1]$. Because of the change in constraint conditions, the information span has a greater coverage, as illustrated in figure 1.

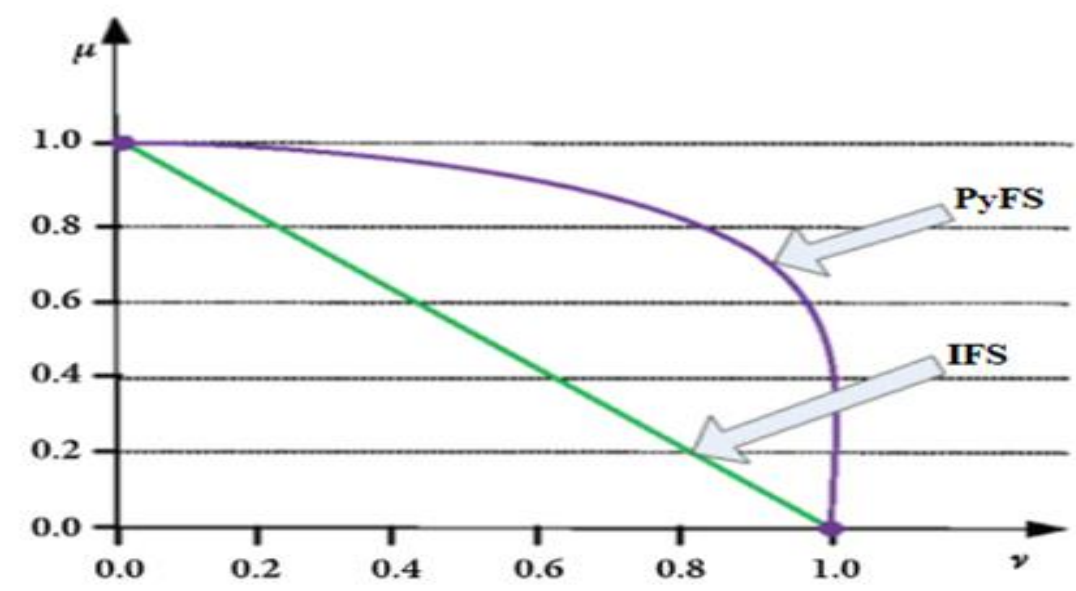

Figure 1: Comparison of Intuitionistic Fuzzy Set and Pythagorean Fuzzy Set

\section{Definition (Akram et al., 2018)}

Let $\mathrm{V}$ be a node set that is not empty.

The Pythagorean Fuzzy graph is abbreviated as $\mathrm{G}=(\mathrm{N}, \mathrm{E})$ where a Pythagorean fuzzy set's mappings $\mathrm{N}: \mathrm{V} \rightarrow[0,1]$ on $\mathrm{V}$ as well as the relationship $\mathrm{E}: \mathrm{V} \times \mathrm{V} \rightarrow[0,1]$ on $\mathrm{V}$ as a result $\mu_{E}\left(a_{1} a_{2}\right) \leq \mu_{N}\left(a_{1}\right) \Lambda \mu_{N}\left(a_{2}\right), \vartheta_{E}\left(a_{1} a_{2}\right) \leq \vartheta_{N}\left(a_{1}\right) \mathrm{V} \vartheta_{N}\left(a_{2}\right)$, for all $a_{1}, a_{2} \in \mathrm{V}, a_{1}, a_{2} \in \mathrm{E}$.

Minimal operator is denoted by $\Lambda$, while the maximum operator is denoted by the letter $\mathrm{V}$.

Definition (Almunajam, A et al., 2021)

The graph $\mathrm{G}=(\mathrm{N}, \mathrm{E})$ is called PyFDG if the node set $\mathrm{N}=\left(\mathrm{V}, \mu_{i}, \vartheta_{i}\right)$ is a Pythagorean Fuzzy Set on a non-empty Pythagorean Fuzzy Set $\mathrm{V}$ and edge set $\mathrm{E}=\left(\mathrm{V} \times \mathrm{V}, \mu_{i, j}, \vartheta_{i, j}\right)$ is based on 
the relation $\mathrm{V}$, the locations of the mappings $\mu_{i}, \vartheta_{i}: \mathrm{V} \rightarrow[0,1]$ and $\mu_{i, j}, \vartheta_{i, j}: \mathrm{V} \times \mathrm{V} \rightarrow[0,1]$ are called the positive and negative membership values for each vertex $v_{i} \in \mathrm{V}$, and each edge $e_{i j}$ $=\left(v_{i}, v_{j}\right) \in \mathrm{V} \times \mathrm{V}$ with the constraint $0 \leq \mu_{i}^{2}\left(v_{i}\right)+\vartheta_{i}^{2}\left(v_{i}\right) \leq 1$, there exist

$$
\begin{aligned}
& \mu_{i, j} \leq \mu_{i}\left(v_{i}\right) \Lambda \mu_{i}\left(v_{j}\right) \\
& \vartheta_{i, j} \leq \vartheta_{i}\left(v_{i}\right) \vee \vartheta_{i}\left(v_{j}\right)
\end{aligned}
$$

In contrast to Pythagorean Fuzzy Graph, Pythagorean Fuzzy Directed Graph does not have a symmetric relation on $\mathrm{V}$.

Definition (Almunajam, A et al., 2021)

Let $N=(\mu, \vartheta)$ be Pythagorean fuzzy number. The formula for calculating its scoring function is as follows:

$$
\mathrm{S}(\mathrm{N})=\mu^{2}-\vartheta^{2}
$$

Example

$\mathrm{G}=(\mathrm{V}, \mathrm{E})$ with vertices $\mathrm{V}=\{\mathrm{a}, \mathrm{b}, \mathrm{c}, \mathrm{d}, \mathrm{e}\}$, and PyFN a= (0.6,0.4), $\mathrm{b}=(0.8,0.4), \mathrm{c}=(0.6,0.2), \mathrm{d}=$ $(0.2,0.1), e=(0.7,0.2)$. The following figure 2 is an example of PyFDG and its index matrix are shown in table 1:

Table 1: Index Matrix of the graph, where $\infty=(0,1)$.

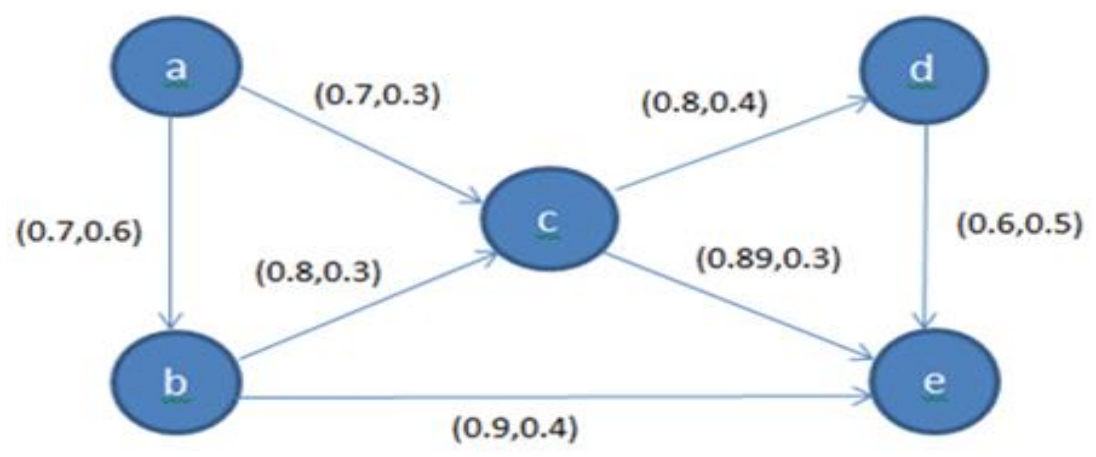

Figure 2: Pythagorean Fuzzy Digraph

Table 1: Index Matrix of the graph, where $\infty=(0,1)$

\begin{tabular}{|c|c|c|c|c|c|}
\hline Vertices & $\mathbf{a}$ & $\mathbf{b}$ & $\mathbf{c}$ & $\mathbf{d}$ & $\mathbf{e}$ \\
\hline $\mathbf{a}$ & $\infty$ & $(0.7,0.6)$ & $(0.7,0.3)$ & $\infty$ & $\infty$ \\
\hline $\mathbf{b}$ & $\infty$ & $\infty$ & $(0.8,0.3)$ & $\infty$ & $(0.9,0.4)$ \\
\hline
\end{tabular}




\begin{tabular}{|c|c|c|c|c|c|}
\hline $\mathbf{c}$ & $\infty$ & $\infty$ & $\infty$ & $(0.8,0.4)$ & $(0.89,0.3)$ \\
\hline $\mathbf{d}$ & $\infty$ & $\infty$ & $\infty$ & $\infty$ & $(0.6,0.5)$ \\
\hline $\mathbf{e}$ & $\infty$ & $\infty$ & $\infty$ & $\infty$ & $\infty$ \\
\hline
\end{tabular}

\section{PYTHAGOREAN FUZZY DIGRAPH ALGORITHM}

The shortest route of a graph was determined using a variety of algorithms, including Bellman-Ford algorithm and the Dijkstra's algorithm. The shortest route between nodes i and j of a Pythagorean Fuzzy Digraph was determined using a new technique. Vertex and edges of a Pythagorean Fuzzy Digraph are assumed as a Pythagorean Fuzzy Number. This section's proposed algorithm encourages researchers to look into a real-world problem.

Pythagorean Fuzzy Digraph $G=(V, E)$ if node $V=\{1=$ Initial node, $2,3, \ldots . . n=$ Final node $\}$ and edge set which connects two vertices by an arrow $V=\{1,2,3, \ldots . n\}$. The path of the Pythagorean Fuzzy Digraph is denoted by $g_{i j}$ and it is defined as $g_{i j}=\{$ weight of the arc which connects node i to node $\mathrm{j}$ \}.

\section{ALGORITHM AND FLOWCHART}

Step-1: Write the Pythagorean Fuzzy weight in the respective arcs such that Pythagorean Fuzzy Weight is $\mu^{2}+\vartheta^{2} \leq 1$.

Step-2: By using Pythagorean Fuzzy Weight, we can calculate the Score Function $\mu^{2}-$ $\vartheta^{2}$ value using definition

Step-3: Set the initial node weight $g(1)=\langle 0,1\rangle$.

Step-4: By using Score Function, we can find the $g(\beta)$ values.

$$
g(\beta)=\left\{\operatorname{Min}_{\alpha<\beta}(g(\alpha)+d(\alpha, \beta))\right\} \text { where } \alpha=1,2,3, \ldots \ldots, \beta=2,3,4, \ldots . .
$$

Step-5: Find the shortest path by using an approach from the ground up. 


\section{FLOW CHART}

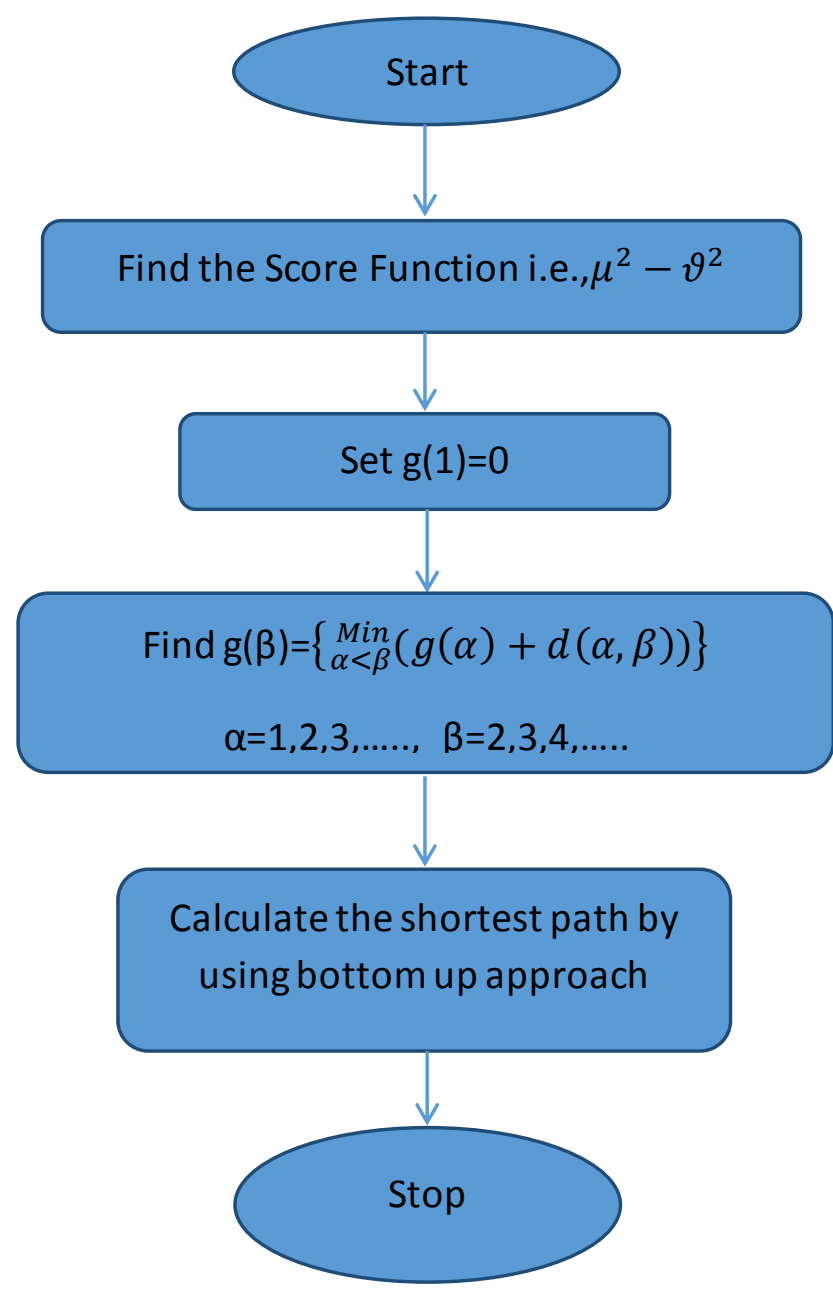

APPLICATION OF PYTHAGOREAN FUZZY DIGRAPH

In Singapore, there has been considerable increase in robotic research during the last few years. A lot of research is being done on Robots that provide services, robots for the military, and Robots to the Rescue, to name a few. However, autonomous robots capable of making complex decisions are uncommon in Singapore. It's pretty difficult to design a self-aware intelligent robot that can go from one location to another inside a prepared map while avoiding obstacles. It comes with numerous obstacles for solving these package delivery systems, which can be implemented in various ride-sharing companies in Singapore and other developing nations, such as Pathao Foods, Uber Eats, and Food Panda. 
Drones and robots, both manual and automatic, have become commonplace in recent years. When the origin and terminals are known, the robot moves in an orderly manner, taking the shortest path possible to deliver the goods in the shortest amount of time.

Assume we have a robot that can deliver packages. It must transport a package from city 1 to city 10 in Singapore using the shortest route available.

The algorithm is used to address a problem of decision-making. It was intended to solve the challenge of finding the shortest path in a graph with a single source. Vertices and edges are found in a graph. If we depict Singapore as a graph with a city/place as a vertex and a route between two cities/places as an edge, we can use this method to determine the shortest routes between any two cities/places or from one city/place to another.

For this situation, we created a Pythagorean fuzzy network (Figure 3), whose arc weight is listed in Table 2.

First let us check whether the Pythagorean Fuzzy Weight is $\mu^{2}+\vartheta^{2} \leq 1$.

Next, we can calculate the Score Function $\mathrm{SF}=\mu^{2}-\vartheta^{2}$ that is shown in the table 3.

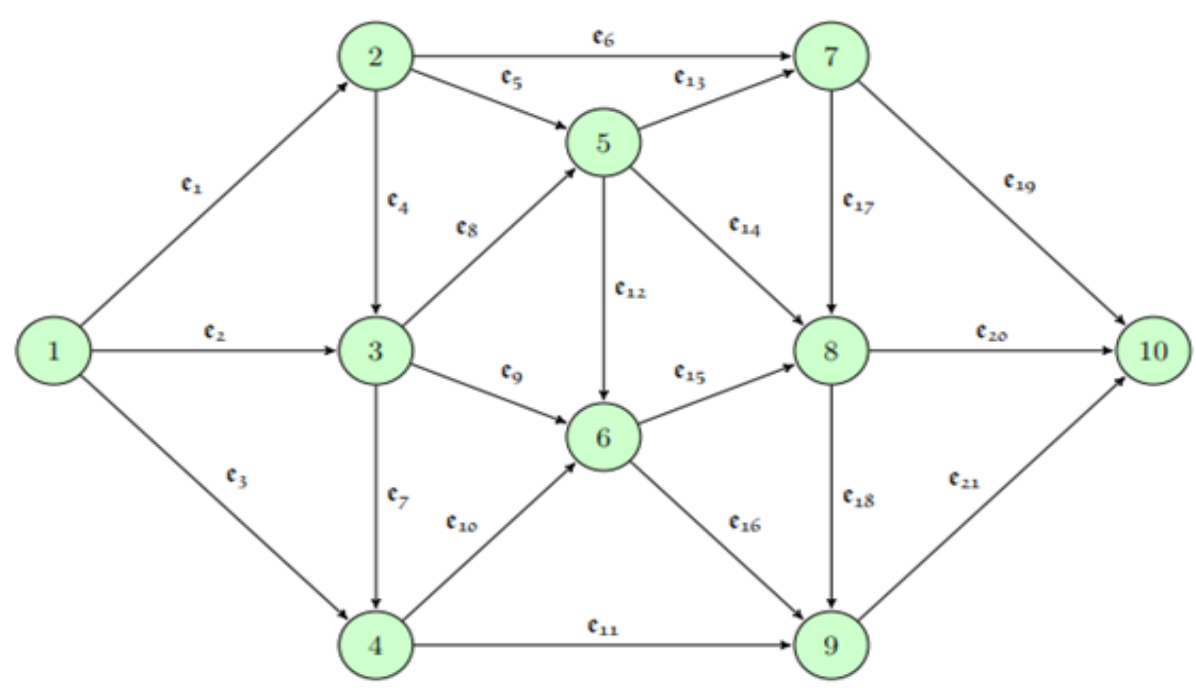

Figure 3: Pythagorean Fuzzy Digraph (PyFDG) 
Table 2Pythagorean fuzzy weights (PyFW)

\begin{tabular}{|c|c|c|c|c|c|}
\hline S.No. & Arc Name & PyFW & S.No. & Arc Name & PyFW \\
\hline $\mathbf{1}$ & $(1,2)$ & $(0.7,0.6)$ & $\mathbf{1 2}$ & $(5,6)$ & $(0.5,0.1)$ \\
\hline $\mathbf{2}$ & $(1,3)$ & $(0.8,0.3)$ & $\mathbf{1 3}$ & $(5,7)$ & $(0.8,0.4)$ \\
\hline $\mathbf{3}$ & $(1,4)$ & $(0.9,0.4)$ & $\mathbf{1 4}$ & $(5,8)$ & $(0.77,0.53)$ \\
\hline $\mathbf{4}$ & $(2,3)$ & $(0.6,0.4)$ & $\mathbf{1 5}$ & $(6,8)$ & $(0.9,0.3)$ \\
\hline $\mathbf{5}$ & $(2,5)$ & $(0.675,0.54)$ & $\mathbf{1 6}$ & $(6,9)$ & $(0.6,0.5)$ \\
\hline $\mathbf{6}$ & $(2,7)$ & $(0.89,0.15)$ & $\mathbf{1 7}$ & $(7,8)$ & $(0.75,0.56)$ \\
\hline $\mathbf{7}$ & $(3,4)$ & $(0.7,0.3)$ & $\mathbf{1 8}$ & $(8,9)$ & $(0.81,0.54)$ \\
\hline $\mathbf{8}$ & $(3,5)$ & $(0.69,0.45)$ & $\mathbf{1 9}$ & $(7,10)$ & $(0.82,0.49)$ \\
\hline $\mathbf{9}$ & $(3,6)$ & $(0.6,0.75)$ & $\mathbf{2 0}$ & $(8,10)$ & $(0.89,0.3)$ \\
\hline $\mathbf{1 0}$ & $(4,6)$ & $(0.59,0.45)$ & $\mathbf{2 1}$ & $(9,10)$ & $(0.92,0.35)$ \\
\hline $\mathbf{1 1}$ & $(4,9)$ & $(0.68,0.56)$ & & & \\
\hline
\end{tabular}

Table 3Score Function

\begin{tabular}{|c|c|c|c|c|c|c|}
\hline S.No. & $\begin{array}{c}\text { Arc } \\
\text { Name }\end{array}$ & PyFW & $\mu$ & $\boldsymbol{\eta}$ & $\mu^{2}+\boldsymbol{\vartheta}^{2} \leq \mathbf{1}$ & $\begin{array}{c}\text { Score } \\
\text { Function } \\
\mu^{2}-\boldsymbol{\vartheta}^{2}\end{array}$ \\
\hline $\mathbf{1}$ & $(1,2)$ & $(0.7,0.6)$ & 0.7 & 0.6 & 0.85 & 0.13 \\
\hline $\mathbf{2}$ & $(1,3)$ & $(0.8,0.3)$ & 0.8 & 0.3 & 0.73 & 0.55 \\
\hline $\mathbf{3}$ & $(1,4)$ & $(0.9,0.4)$ & 0.9 & 0.4 & 0.97 & 0.65 \\
\hline $\mathbf{4}$ & $(2,3)$ & $(0.6,0.4)$ & 0.6 & 0.4 & 0.52 & 0.20 \\
\hline $\mathbf{5}$ & $(2,5)$ & $(0.675,0.54)$ & 0.675 & 0.54 & 0.75 & 0.16 \\
\hline $\mathbf{6}$ & $(2,7)$ & $(0.89,0.15)$ & 0.89 & 0.15 & 0.81 & 0.77 \\
\hline $\mathbf{7}$ & $(3,4)$ & $(0.7,0.3)$ & 0.7 & 0.3 & 0.58 & 0.40 \\
\hline $\mathbf{8}$ & $(3,5)$ & $(0.69,0.45)$ & 0.69 & 0.45 & 0.68 & 0.27 \\
\hline $\mathbf{9}$ & $(3,6)$ & $(0.6,0.75)$ & 0.6 & 0.75 & 0.92 & -0.20 \\
\hline $\mathbf{1 0}$ & $(4,6)$ & $(0.59,0.45)$ & 0.59 & 0.45 & 0.55 & 0.15 \\
\hline $\mathbf{1 1}$ & $(4,9)$ & $(0.68,0.56)$ & 0.68 & 0.56 & 0.78 & 0.15 \\
\hline $\mathbf{1 2}$ & $(5,6)$ & $(0.5,0.1)$ & 0.5 & 0.1 & 0.26 & 0.24 \\
\hline $\mathbf{1 3}$ & $(5,7)$ & $(0.8,0.4)$ & 0.8 & 0.4 & 0.80 & 0.48 \\
\hline
\end{tabular}




\begin{tabular}{|c|c|c|c|c|c|c|}
\hline & $(5,8)$ & $(0.77,0.53)$ & 0.77 & 0.53 & 0.87 & 0.31 \\
\hline $\mathbf{1 5}$ & $(6,8)$ & $(0.9,0.3)$ & 0.9 & 0.3 & 0.90 & 0.72 \\
\hline $\mathbf{1 6}$ & $(6,9)$ & $(0.6,0.5)$ & 0.6 & 0.5 & 0.61 & 0.11 \\
\hline $\mathbf{1 7}$ & $(7,8)$ & $(0.75,0.56)$ & 0.75 & 0.56 & 0.88 & 0.25 \\
\hline $\mathbf{1 8}$ & $(8,9)$ & $(0.81,0.54)$ & 0.81 & 0.54 & 0.95 & 0.36 \\
\hline $\mathbf{1 9}$ & $(7,10)$ & $(0.82,0.49)$ & 0.82 & 0.49 & 0.91 & 0.43 \\
\hline $\mathbf{2 0}$ & $(8,10)$ & $(0.89,0.3)$ & 0.89 & 0.3 & 0.88 & 0.70 \\
\hline $\mathbf{2 1}$ & $(9,10)$ & $(0.92,0.35)$ & 0.92 & 0.35 & 0.97 & 0.72 \\
\hline
\end{tabular}

Step 1: Set $g(1)=0$

Step 2: $g(2)=\operatorname{Min}\{g(1)+d(1,2)\}=\operatorname{Min}\{0+0.13\}=\operatorname{Min}\{0.13\}=0.13 \Rightarrow g(2)=0.13$

Step 3: $g(3)=\operatorname{Min}\{g(1)+d(1,3), g(2)+d(2,3)\}=\operatorname{Min}\{0+0.55,0.13+0.20\}=\operatorname{Min}\{0.55,0.33\}$ $=0.33 \Rightarrow \mathrm{g}(3)=0.33$

Step 4: $g(4)=\operatorname{Min}\{g(1)+d(1,4), \quad g(3)+d(3,4)\}=\operatorname{Min}\{0+0.65,0.33+0.40\}=\operatorname{Min}\{0.65$, $0.73\}=0.65 \Rightarrow g(4)=0.65$

Step 5: $g(5)=\operatorname{Min}\{g(2)+d(2,5), \quad g(3)+d(3,5)\}=\operatorname{Min}\{0.13+0.16,0.33+0.27\}=\operatorname{Min}\{0.29$, $0.60\}=0.29 \Rightarrow \mathrm{g}(5)=0.29$

Step 6: $g(6)=\operatorname{Min}\{g(3)+d(3,6), g(4)+d(4,6), g(5)+d(5,6)\}=\operatorname{Min}\{0.33-0.20,0.65+0.15$, $0.29+0.24\}=\operatorname{Min}\{0.13,0.80,0.53\}=0.13 \mathrm{~g}(6)=0.13$

Step 7: $g(7)=\operatorname{Min}\{g(2)+d(2,7), \quad g(5)+d(5,7)\}=\operatorname{Min}\{0.13+0.77,0.29+0.48\}=\operatorname{Min}\{0.90$, $0.77\}=0.77 \Rightarrow g(7)=0.77$

Step 8: $g(8)=\operatorname{Min}\{g(5)+d(5,8), g(6)+d(6,8), g(7)+d(7,8)\}=\operatorname{Min}\{0.29+0.31,0.13+0.72$, $0.77+0.25\}=\operatorname{Min}\{0.60,0.85,1.02\}=0.60 \Rightarrow \mathrm{g}(8)=0.60$

Step 9: $g(9)=\operatorname{Min}\{\mathrm{g}(4)+\mathrm{d}(4,9), \mathrm{g}(6)+\mathrm{d}(6,9), \mathrm{g}(8)+\mathrm{d}(8,9)\}=\operatorname{Min}\{0.65+0.15,0.13+0.11$, $0.60+0.36\}=\operatorname{Min}\{0.60,0.85,1.02\}=0.24 \Rightarrow g(9)=0.24$

Step 10:g(10)= Min $\{g(7)+d(7,10), \quad g(8)+d(8,10), g(9)+d(9,10)\}=\operatorname{Min}\{0.77+0.43$, $0.60+0.70,0.24+0.72\}=\operatorname{Min}\{1.20,1.30,0.96\}=0.96 \Rightarrow g(10)=0.96$ 
The shortest path of PyFDG is $1 \rightarrow 2 \rightarrow 3 \rightarrow 6 \rightarrow 9 \rightarrow 10$

Shortest Pythagorean Fuzzy Path from City 1 to City j in Singapore is given in Table 4 and the highlighted lines in PyFDG indicate the Pythagorean Fuzzy Shortest Path from City 1 to City $\mathrm{j}$ in Singapore as shown in Figure 4.

Table 4Pythagorean formulas with the shortest length the weights of a squishy path.

\begin{tabular}{|c|c|c|}
\hline Node $\mathbf{j}$ & $\begin{array}{c}\text { Shortest Pythagorean Fuzzy path from } \\
\mathbf{1} \mathbf{~ t o} \mathbf{j}\end{array}$ & $\mathbf{g}(\boldsymbol{\beta})$ \\
\hline $\mathbf{2}$ & $1 \rightarrow 2$ & 0.13 \\
\hline $\mathbf{3}$ & $1 \rightarrow 2 \rightarrow 3$ & 0.33 \\
\hline $\mathbf{4}$ & $1 \rightarrow 4$ & 0.65 \\
\hline $\mathbf{5}$ & $1 \rightarrow 2 \rightarrow 5$ & 0.29 \\
\hline $\mathbf{6}$ & $1 \rightarrow 2 \rightarrow 3 \rightarrow 6$ & 0.13 \\
\hline $\mathbf{7}$ & $1 \rightarrow 2 \rightarrow 5 \rightarrow 7$ & 0.77 \\
\hline $\mathbf{8}$ & $1 \rightarrow 2 \rightarrow 5 \rightarrow 8$ & 0.60 \\
\hline $\mathbf{9}$ & $1 \rightarrow 2 \rightarrow 3 \rightarrow 6 \rightarrow 9$ & 0.24 \\
\hline $\mathbf{1 0}$ & $1 \rightarrow 2 \rightarrow 3 \rightarrow 6 \rightarrow 9 \rightarrow 10$ & 0.96 \\
\hline
\end{tabular}

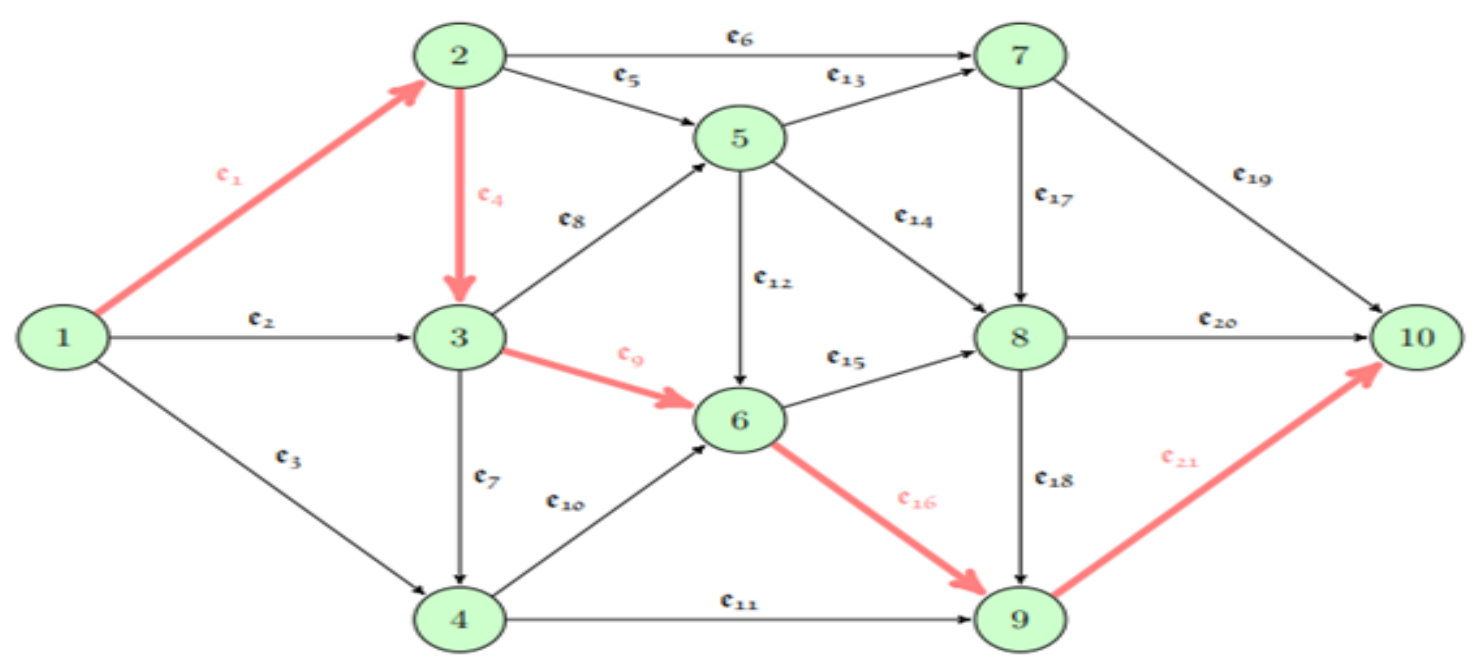

Figure 4: The Pythagorean Fuzzy Shortest Path 


\section{CONCLUSIONS}

The Pythagorean fuzzy set has been used to cope with uncertainty in a variety of domains. This set was used to discover the shortest path in a graph structure. However, the Pythagorean fuzzy set has not been addressed in relation to digraph. As a result, the Pythagorean fuzzy digraph has been defined. For computation, the score function is used to defuzzify crisp values that have been fuzzified. The proposed approach is used to explore a real-world problem. The Pythagorean fuzzy diagraph will be used to investigate different complicated problems in the future.

\section{REFERENCES}

Rosenfeld, A.,(1975). Fuzzy Graphs, Fuzzy Sets and their Applications, Zadeh, L.A, Fu, K.S., Shimura, M., Eds.; Academic Press, New York, NY, USA.

Atanassov, K., (1986). Intuitionistic fuzzy sets, Fuzzy Sets and Systems 20, 87-96.

Atanassov, K., (1988). Review and new results on intuitionistic fuzzy sets preprint Im MFAIS-1-88, Sofia 5, 1.

Atanassov.K., and Stoeva,S.,(1983).Intuitionistic fuzzy set, in: Polish Syrup. On Interval \& Fuzzy Mathematics, Poznan, 23-26.

Zadeh,L.A., (1985). Fuzzy Sets, Information and Control 18, 338-353.

Shannon, A., Atanassov, K., (2006).On a generalization of intuitionistic fuzzy graphs. NIFS $12,24-29$.

Parvathi,R., Karunambigai,M.,(2006). Intuitionistic fuzzy graphs, In Computational Intelligence, Theory andApplications, Springer: Berlin, Germany, 139-150.

Parvathi, R., Thamizhendhi, G., (2010).Domination in intuitionistic fuzzy graphs, Notes Intuit. Fuzzy Sets 16, 39-49.

Parvathi,R., Karunambigai,M., Atanassov,K., (2009). Operations on intuitionistic fuzzy graphs, In Proceedingsof the 2009 IEEE International Conference on Fuzzy Systems, Jeju 
Island, Korea, 20-24 August, 1396-1401.

Yager,R.R.,(2013).Pythagorean fuzzy subsets. In: Proceedings of the Joint IFSA World Congress and NAFIPS Annual Meeting, Edmonton, Canada, 57-61.

Yager,R.R.,Abbasov,A.M.,(2013).Pythagorean membership grades, complex numbers, and decisionmaking. Int J IntellSyst 28(5), 436-452.

Yager,R.R.,(2014). Pythagorean membership grades in multi-criteria decision making. IEEE Trans Fuzzy Syst. 22(4), 958-965.

Xu,Z.,Hu,H.,(2010). Projection models for intuitionistic fuzzy multiple attribute decision making, Int. J. Inf. Technol. Decis. Mak. 9, 267-280.

Zhang,X., Xu,Z., (2014).Extension of TOPSIS to multiple criteria decision making with Pythagorean fuzzy sets.Int J IntellSyst 29(12), 1061-1078.

Akram,M., Habib,A., Ilyas,F., Dar,J.M., (2018). Specific types of Pythagorean fuzzy graphs and application to decision-making. Math.Comput.Appl. 23, 42. https://doi.org/10.3390/mca23030042

Akram,M., MohsanDar,J., Naz,S., (2019). Certain graphs under Pythagorean fuzzy environment , Complex \& Intelligent Systems 5:127-144. https://doi.org/10.1007/s40747-018-0089-5

Özdemir, Y.S., Üsküdar, A,. (2020). Strategy selection by using interval type-2 fuzzy mcdm and an application. Journal of Engineering Research, Aug 13;8(3), 172-189.

Shahzad, M., (2020). Fuzzy Logic Based Prediction Algorithm Using Nearest Neighborhood Clustering. Journal of Engineering Research, Aug 13; 8(3), 136-152. Naz,S., Ashraf ,S., Akram,M., (2018).A novel approach to decision making with Pythagorean fuzzy information. Mathematics 6(6):95.

Parimala,M., Broumi,S., Karthika,M., (2019). A Network Shortest Path Algorithm via Hesitancy Fuzzy Digraph, Journal of New Theory, 27, 52-62. 
Broumi,S.,Talea,M.,Bakali,A.,Smarandache,F.,Nagarajan,D.,Lathamaheswari,M.,

Parimala,M.,(2019).Shortest path problem in fuzzy, intuitionistic fuzzy and neutrosophic environment: an overview, Complex \& intelligent Systems, Springer International Publishing, 1-8.

Mordeson, J.N., Chang-Shyh,P,. (1994).Operations on fuzzy graphs. Inf. Sci., 79, 159-170.

NagoorGani, A., Radha,K., (2008).On regular fuzzy graphs. J. Phys. Sci. 12, 33-44.

Karunambigai,M.G.,Rangasamy,P.,Atanassov,K., and Palaniappan,N., (2018).An

intuitionistic fuzzy graph method for finding the shortest paths in networks, In: Theoretical Advances and Applications of Fuzzy Logic and Soft Computing, 3-10.

Parimala,M., Almunajam,A., Karthika,M., Alshammari,I., (2021). Pythagorean Fuzzy Digraphs and Its Application in Healthcare Center, Journal of Mathematics, Sep 7,1-6. 